\title{
The influence of lexical and conceptual constraints on reading mixed-language sentences: Evidence from eye fixations and naming times
}

\author{
JEANETTE ALTARRIBA \\ State University of New York, Albany, New York \\ JUDITH F. KROLL \\ Pennsylvania State University, University Park, Pennsylvania \\ and \\ ALEXANDRA SHOLL and KEITH RAYNER \\ University of Massachusetts, Amherst, Massachusetts
}

\begin{abstract}
In two experiments, we explored the degree to which sentence context effects operate at a lexical or conceptual level by examining the processing of mixed-language sentences by fluent SpanishEnglish bilinguals. In Experiment 1, subjects' eye movements were monitored while they read English sentences in which sentence constraint, word frequency, and language of target word were manipulated. A frequency $\times$ constraint interaction was found when target words appeared in Spanish, but not in English. First fixation durations were longer for high-frequency Spanish words when these were embedded in high-constraint sentences than in low-constraint sentences. This result suggests that the conceptual restrictions produced by the sentence context were met, but that the lexical restrictions were not. The same result did not occur for low-frequency Spanish words, presumably because the slower access of low-frequency words provided more processing time for the resolution of this conflict. Similar results were found in Experiment 2 using rapid serial visual presentation when subjects named the target words aloud. It appears that sentence context effects are influenced by both semantic/conceptual and lexical information.
\end{abstract}

The extent to which contextual information influences word recognition during sentence comprehension has been studied extensively for what it might tell us about the general nature of language processing. There are now many demonstrations that words are processed faster when preceded by a constraining context than when preceded by a neutral context. Evidence of facilitation in processing a contextually constrained target word has been obtained in experiments using naming (Stanovich \& West,

J.A. was supported by National Institutes of Health (NIH) Grant HD07327 for postdoctoral training in psycholinguistics at the University of Massachusetts, Amherst, and by a faculty research award from the State University of New York at Albany. K.R. was supported by a research scientist award from the National Institute of Mental Health (NIMH) (Grant MH01255). This research was also supported by NIMH Grant MH44246 and National Science Foundation (NSF) Grant DBS9211863, awarded to J.F.K., and by NIH Grant HD26765 and NSF Grant DBS-912375, awarded to K.R. Portions of these data were presented at the annual meeting of the Psychonomic Society, San Francisco, 1991, and the XXVth International Congress of Psychology, Brussels, 1992. We would like to thank Charles E. Clifton, John Huitema, and Gary Raney for their assistance in data analysis; Janyce Berg and Oysim Chin for their assistance with data entry; and Mary Potter, Michael Masson, and an anonymous reviewer for their helpful comments on an earlier version of the paper. Correspondence should be addressed to J. Altarriba, Department of Psychology, State University of New York, Albany, NY 12222 (e-mail: ja087@csc.albany.edu).
1983) and lexical decision (Fischler, 1985; Fischler \& Bloom, 1980; Schwanenflugel \& Shoben, 1985) tasks. In addition, experiments in which readers' eye movements are recorded have demonstrated that readers skip over constrained words more than they skip over unconstrained words and that fixation times on constrained words are shorter than they are on unconstrained words (Balota, Pollatsek, \& Rayner, 1985; Ehrlich \& Rayner, 1981; Schustack, Ehrlich, \& Rayner, 1987).

There is general agreement that contextual information facilitates reading, but not on the source of the facilitation. At issue is whether the facilitation is due to lexical or to semantic/conceptual variables or to an interaction of these variables. Although arguments have been made in support of both lexical and semantic/conceptual information being the source of the effect, more recent findings suggest that the facilitatory effect of context is due to an interaction of lexical retrieval processes and processes due to higher level influences. These higher level influences can be semantic or conceptual, and are also referred to as message-level variables. We will describe three sets of results that are consistent with this view.

First, Schustack et al. (1987) used a multiple-task approach to provide evidence that contextual facilitation is due to both lexical and message-level sources. In their studies, they manipulated both global (recency of prior 
mention of a target word) and local (degree of semantic constraint from the preceding verb) aspects of the stimuli. When a naming task was used, where integration of the target word into the discourse structure was not required by the task, Schustack et al. found that only the degree of semantic constraint of the preceding verb speeded naming. However, when they recorded eye movements during reading, where integration of the target word was required because the text continued after the target, they found that both recency of prior mention and degree of semantic constraint of the preceding verb speeded processing of the target.

Second, converging evidence for the position that a message-level representation interacts with the ongoing process of lexical retrieval during sentence comprehension has been reported in a study by Morris (1994; see also Duffy, Henderson, \& Morris, 1989) in which she manipulated lexical and message-level information independently. For example, in a sentence including the nouns gardener and barber and the verb trimmed, eye fixation times on the target word mustache were facilitated only if barber was the agent of trimmed. In the case in which gardener was the agent of trimmed, no facilitation in fixation time was reported, although the lexical content of the sentence was similar. These results suggest that context effects may be the result of an interaction between lexical access and the message-level representation.

A final source of evidence concerning the interaction of context and lexical retrieval comes from studies examining lexical access in sentence contexts that vary in the degree to which they constrain a particular target word. In models of sentence constraint effects, it is generally assumed that constraint operates at a semantic or conceptual level. Schwanenflugel and LaCount (1988) examined the joint influence of sentence constraint and semantic relatedness on the processing of upcoming words. In their study, subjects showed difficulty in making lexical decisions to a word that was semantically related to the expected word in a highly constrained context, as in the following example: "The landlord was faced with a strike by the residents." The expected word in this case was tenants.

Schwanenflugel and LaCount (1988) proposed a feature restriction model to explain the effects of sentence constraint. Sentence constraint is said to determine the number of featural restrictions that subjects generate as a result of reading the context. According to this view, readers generate fewer featural restrictions for low-constraint sentences than for high-constraint sentences. Thus, given the low-constraint sentence, "Hank reached into his pocket to get the __ a reader might generate few featural restrictions like [frequently found in pockets] and [small]. When only a minimal number of featural restrictions is generated from a sentence, a greater number of possible completions will match the description and show facilitation. For high-constraint sentences like, "The tired mother gave her dirty child a ," the reader might generate a relatively larger number of features such as [cleans], [common to children], [can be given by mothers], [taken by people], and so on. In this case, very few final words have the potential to match the complete description set up by the context. Facilitation will be shown only for those final words whose semantic representations do not mismatch any of the feature restrictions generated from the sentence context. Thus, related words, whose semantic descriptions mismatch on a few features, will not show facilitation from the context.

Although the above studies indicate that semantic feature restrictions influence the processing of upcoming words in a sentence, it is possible that lexical restrictions can also influence sentence processing. The goal of the two experiments reported here was to determine whether sentence context leads solely to the specification of abstract semantic features, or whether access to lexical features is also determined by sentence context. A new source of evidence was used here-the processing of mixedlanguage sentences by fluent Spanish-English bilinguals. We investigated the degree to which sentence constraint influences word recognition in English and in Spanish. Consider the English sentences shown in Table 1. In the high-constraint sentence, the sentence context strongly constrains the target word money. In the low-constraint sentence, the word money is a plausible lexical item at the point at which it occurs, but it has not been constrained by the preceding context.

In the present experiments, we manipulated the language in which expected and plausible words appeared in high- and low-constraint sentences (see examples in Table 1). The sentence contexts in both experiments always appeared in English, and for half of the sentences the critical target words also appeared in English. For the remaining half of the sentences, however, the critical target words appeared in Spanish. Past research on bilingual language representation suggests that fluent bilinguals can take advantage of common conceptual representations that are shared by their two languages (Altarriba, 1992; Chen \& Ng, 1989; Glanzer \& Duarte, 1971; Meyer \& Ruddy, 1974; Potter, So, von Eckardt, \& Feldman, 1984; Schwanenflugel \& Rey, 1986; Tzelgov \& Henik, 1989). Lexical representations for each of a bilingual's two languages may be distinct, but once second language learners acquire sufficient proficiency in the second language,

Table 1

\begin{tabular}{cc}
$\begin{array}{c}\text { Sample High- and Low-Constraint Sentences Used } \\
\text { in Experiments } 1 \text { and } 2\end{array}$ & Sentence \\
\hline $\begin{array}{c}\text { English Target Words } \\
\text { High constraint }\end{array}$ & $\begin{array}{c}\text { "He wanted to deposit all of his money at } \\
\text { the credit union." } \\
\text { "He always placed all of his money on a sil- } \\
\text { ver dish on his dresser." }\end{array}$ \\
Low constraint & $\begin{array}{c}\text { Spanish Target Words } \\
\text { High constraint }\end{array}$ \\
Low constraint & $\begin{array}{c}\text { "He wanted to deposit all of his dinero at } \\
\text { the credit union." } \\
\text { ver dish on his dresser." }\end{array}$ \\
\hline
\end{tabular}


concepts are thought to be stored in an abstract memory system (Chen \& Leung, 1989; Kroll \& Curley, 1988; Kroll \& Sholl, 1992; Kroll \& Stewart, 1994; Snodgrass, 1984). Although not all words in a bilingual's two languages necessarily share precise translation equivalents, past research suggests that at least concrete nouns (like those used as target words in the present experiments) are likely to activate the same meanings across languages (see, e.g., de Groot, 1992).

If sentence constraint acts at a conceptual level to specify a set of abstract semantic features, then as long as subjects are highly fluent in both English and Spanish, the effects of sentence constraint should not differ dramatically for targets in the two languages. However, if sentence constraint also acts at a lexical level to specify the particular word that might satisfy the generated restrictions, then Spanish targets should violate those lexical-level expectations and produce interference in processing. ${ }^{1}$

The current experiments used materials similar to those shown in Table 1. Whereas Schwanenflugel and LaCount (1988) varied constraint and semantic relatedness, we also examined word frequency. Thus, in addition to the language of the target word and sentence constraint, the frequency of the target word was also manipulated. Word frequency was included as a variable because frequency effects are typically attributed to lexical-level processes rather than conceptual-level processes (see, e.g., Monsell, 1991, for a recent discussion of frequency effects). Thus, if a highly constrained sentence context generates expectations solely for semantic feature restrictions, frequency should not interact with sentence constraint. However, if expectations for specific lexical representations develop as sentence processing proceeds, we might expect word frequency to interact with sentence constraint. Furthermore, if those lexical representations are language specific, we would expect to find this interaction for the mixed-language sentences but not for the all-English sentences.

In the first experiment, we monitored subjects' eye movements while they read the experimental sentences as an on-line measure of language processing during normal, silent reading (Rayner \& Pollatsek, 1989; Rayner, Sereno, Morris, Schmauder, \& Clifton, 1989). In the second experiment, we presented the same sentences, one word at a time using the rapid serial visual presentation (RSVP) procedure (see Duffy et al., 1989). The subject's task in the RSVP experiment was to name the capitalized target word in each sentence. Our aim was to use a converging set of methods to examine context effects and to determine the locus of the sentence constraint effect.

\section{EXPERIMENT 1}

\section{Eye Movements During Mixed-Language Reading}

In Experiment 1 we examined the effects of sentence constraint, word frequency, and language of a target word on fixation times during a sentence-reading task. Sentences such as those shown in Table 1 were presented to subjects, one at a time, and their eye movements were recorded while they read.
The eye movement methodology provides a rich record of data concerning the time course of processing during reading. The dependent variables that we will report are (1) first fixation duration, (2) gaze duration, and (3) the probability of skipping the target word. First fixation is the duration of the first fixation made on a particular word (independent of the number of fixations that are made on the word), while gaze duration includes the sum of all of the fixations made on a word before the reader leaves that word. Like first fixation duration and gaze duration, the probability of skipping a target word is a first pass effect. The decision of whether to fixate or skip a target word occurs early in the processing of a word (i.e., when preliminary processing is done of a target word in parafoveal vision). As noted earlier, prior research has shown that target words are constrained by the context are skipped more frequently than words that are not constrained by the context (Balota et al., 1985; Ehrlich \& Rayner, 1981).

Gaze duration and first fixation tend to be correlated with each other; both measures are included here as they may reflect different stages of processing. It has been argued that the first fixation measure reflects an early stage in processing while gaze durations indicate a greater level of semantic integration and postlexical processing (Inhoff, 1984; see Rayner \& Pollatsek, 1989, for alternative arguments). While most studies have reported similar effects of a variable on first fixation duration and gaze duration, there have been instances in which different patterns of effects have been obtained for the two measures (see Inhoff, 1984; Inhoff \& Rayner, 1986; Pollatsek, Lesch, Morris, \& Rayner, 1992). When such dissociations occur, useful information can be obtained about the time course of processing. By including both measures we can examine, for example, the degree to which processing a Spanish target word in a highly constrained context requires more fixation time than processing an English target word in the same context. As noted above, prior research has demonstrated that fixation times on words that are highly predictable in a sentence context are shorter than fixation times on words that are less predictable (Balota et al., 1985; Ehrlich \& Rayner, 1981).

Prior research (Inhoff \& Rayner, 1986; Rayner \& Duffy, 1986; Rayner et al., 1989) has also demonstrated that all three of the measures mentioned above are influenced by word frequency. For example, Rayner and Duffy (1986) found that first fixations were about $30 \mathrm{msec}$ longer on low-frequency words than on high-frequency words (matched on word length), and gaze durations were about $80 \mathrm{msec}$ longer. Furthermore, under certain circumstances, readers tend to skip high-frequency words more often than low-frequency words (Rayner, Sereno, \& Raney, in press).

Because it was essential that subjects in this experiment be highly fluent in both English and Spanish, two different measures of their language proficiency were administered. The first measure was a performance task in which subjects' eye movements were recorded while they read a passage of text in English and another in Spanish. This performance measure was administered prior to 
the experimental session. The second measure was a language history questionnaire in which subjects were asked to provide information about their language experience and also to rate their fluency in reading and speaking their second language. The questionnaire was administered following the experimental session. Both measures were used to determine the relative fluency of the subjects in both English and Spanish.

\section{Method}

\section{Subjects}

The subjects were 32 native Spanish speakers who had lived in the United States for an average of 9.3 years. They were sampled from the population of Spanish-English bilingual students at the University of Massachusetts and were highly proficient in both English and Spanish. All subjects had normal, uncorrected vision and had never before participated in an eye movement experiment. They were paid $\$ 6.00$ an hour for their participation, and an experimental session lasted approximately $1 \mathrm{~h}$.

\section{Materials}

Passages. Two English passages and their Spanish translations were chosen from the bilingual reading teacher's manual of Barrera and Crawford (1987). All Spanish materials used included the appropriate accent marks and characteristics of Spanish orthography. Each subject was asked to read one passage in English and a second, different passage in Spanish. The order of presentation of paragraphs was counterbalanced across subjects so that for half of the subjects an English passage was followed by a Spanish passage, and the reverse was true for the other half of the subjects Following each passage, subjects were presented with a comprehension question to encourage them to pay close attention while reading.

Sentences. A set of 32 high-frequency words and 32 lowfrequency words was chosen from the word frequency norms of Kučera and Francis (1967). The high-frequency words had a mean frequency of 161 and ranged from 60 to 492 per million. The lowfrequency words had a mean frequency of 7 and ranged from 1 to 13 per million. Each English word was translated into Spanish for a total of 64 word pairs. ${ }^{2}$ To verify that the grouping of words into high- and low-frequency categories created similar categories for the English and Spanish target words, the frequency of the Spanish translations was taken from the Juilland and Chang-Rodriguez (1964) norms. The Spanish frequency values are based on a count of number of occurrences per 500,000 words (in contrast to the $\mathrm{Ku}$ čera and Francis, 1967, norms, which were based on occurrences per million). The high-frequency Spanish words had a mean frequency of 75 per 500,000 , and the low-frequency Spanish words had a mean frequency of 5 per $500,000 .{ }^{3}$ The mean length of English target words was 5.9 letters for low-frequency targets and 5.8 letters for high-frequency targets; for Spanish target words, the lengths were 6.2 letters and 6.0 letters for low- and high-frequency targets, respectively. Thus, the English and Spanish target words were highly overlapping in terms of word frequency and word length, and it is unlikely that any variations between languages would account for frequency or language differences in the experiments.

Two sentences were generated for each of the 64 word pairs so that one of the sentences was of high constraint and the other was of low constraint. The sentences were created so that the proper syntax was maintained across languages. The target words appeared roughly in the middle of each sentence, and the target word was always congruous within the sentence context, regardless of language. Sentence completion norms were gathered using a modified cloze procedure in which a group of 30 native English speakers was presented the sentence frame up to the target word and asked to supply one completion word for each sentence in English
(Bloom \& Fischler, 1980). The average cloze frequency for the most expected word in the high-constraint sentences was $70 \%$ for both high-frequency words $(S D=.28)$ and low-frequency words $(S D=.32)$. The average cloze frequency for the intended target word in the low-constraint sentences was $7 \%$ for high-frequency words $(S D=.12)$ and $3 \%$ for low-frequency words $(S D=.10)$. This difference was not significant $(p>.05$ ). There was a significant difference between the mean cloze frequency of items appearing in high-constraint sentences $(70 \%)$ and items appearing in lowconstraint sentences $(5 \%)[t(63)=16.43, p<.001]$. The sentences used are listed in the Appendix.

From each of the 64 English-Spanish word pairs used, a total of four sentences was produced: two high-constraint sentences, one with an English target word and one with its Spanish translation; and two low-constraint sentences, one with an English target word and one with its Spanish translation. Therefore, a total of 256 sentences was generated. These sentences were counterbalanced across four stimulus lists such that eight sentences of each type appeared on each list for a total of 64 sentences in each stimulus list.

The 64 sentences were divided into eight blocks. One sentence from each of the eight conditions appeared in each block of eight trials. A comprehension question appeared following one of the sentences within each block to ensure that subjects were paying attention. No sentence or target word in English or in Spanish was repeated within a single list. The sentences were presented in a different random order for each subject, and each subject saw only one list.

\section{Apparatus and Procedure}

The paragraphs and sentences were displayed on a Sony Trinitron 1302 monitor interfaced with an Epson Equity III computer. The computer was also interfaced with a Fourward Technologies Dual Purkinje Generation V Eyetracker. This eyetracker has a resolution of less than $10^{\prime}$ of arc and was used to monitor subjects' eye movements while they read. Viewing was binocular, with movements recorded from the subject's right eye. The position of the eye was sampled every millisecond by the computer. The subjects were seated approximately $62 \mathrm{~cm}$ from the viewing screen, and 4 characters equaled $1^{\circ}$ of visual angle.

The 64 target sentences were presented on separate trials over one to two lines, with up to 72 characters on a single line. The target word was never the first or the last word on a line, and was not highlighted in any way.

At the start of each experimental session, a bite bar was made for each subject in order to minimize head movements. The bite bar was then attached to a stationary vertical bar located to the left of the eyetracker. The instructions were then explained to the subject, and the eyetracker was calibrated. Subjects were shown a calibration pattern before each trial of the experiment.

Prior to the experimental session, each subject read the two passages, one at a time, on the computer screen. After each passage, the word question appeared on a blank screen, below where the passage had appeared. A statement appeared on the next line. Subjects were instructed to press a right-hand lever if the statement was true and a left-hand lever if the statement was false. If the response was incorrect, the word error appeared on the screen. Following the second passage, subjects read two short sentences as practice for the main part of the experiment. These sentences did not appear on any experimental list. One sentence was all in English and a second contained a Spanish word.

In the main part of the experiment, subjects were told that they would be seeing sentences, one at a time, and that a question would appear following some of the sentences. Again, the calibration pattern appeared before each trial, and subjects were told that they could take a break whenever this pattern was on the screen.

After the eye-tracking portion of the experiment, the subjects were asked to complete a 2-page language history questionnaire in which they were asked to give self-ratings on a 10-point scale of 
their ability to read and speak in English and in Spanish $(1=$ not fluent, $10=$ very fluent).

\section{Results and Discussion}

A summary of subjects' language experience can be found in Table 2. The subjects were native Spanish speakers with a mean age of 22.3 years and an average of 15.9 years experience with the English language. They rated themselves higher in their ability to read and write in Spanish than in English $[t(31)=2.03, p<.05]$. They also rated themselves higher in their ability to speak in Spanish than in English $[t(31)=3.04, p<.01]$. However, on both measures and in both languages, subjects reported mean ratings on the high end of the scale (i.e., in excess of 8 on a 10 -point scale).

\section{Passages}

The eye movement data gathered on English and Spanish passages were used as a performance measure in order to better assess subjects' relative reading abilities in their two languages. The dependent measures presented in Table 3 for these passages include average fixation duration, average forward saccade length, average regressive saccade length, and reading rate in each language. The eye fixation measures were quite representative of skilled readers of English (Rayner, 1978). An analysis of the data revealed no significant differences across languages in any of these measures $(p s>.05)$. These results thus suggest that, despite their higher rating for language ability in Spanish than in English, the subjects were highly fluent in both languages and, hence, relatively balanced bilinguals.

\section{Sentences}

The data with respect to the target words were analyzed to examine (1) the probability of skipping the target word, (2) first fixation duration (the duration of the first fixation on the target word), and (3) gaze duration (the sum of all fixations on a word prior to fixating on another word). Fixation durations shorter than $140 \mathrm{msec}$ were excluded from the analyses (about $2 \%$ of the trials); research by Morrison (1984) has demonstrated that when readers make such short fixations on a word, it is highly likely that much of the processing associated with that word is accomplished on the prior fixation. Trials
Table 3

Average Fixation Duration, Mean Forward and Regressive Saccade Length, and Reading Rate for English and Spanish Passages in Experiment 1

\begin{tabular}{lcc}
\hline & \multicolumn{2}{c}{ Passages } \\
\cline { 2 - 3 } \multicolumn{1}{c}{ Measure } & English & Spanish \\
\hline Average fixation duration (milliseconds) & 257 & 255 \\
Mean forward saccade length (letter spaces) & 8.4 & 8.9 \\
Mean regressive saccade length & 6.7 & 6.3 \\
Reading rate (words per minute) & 331 & 348 \\
\hline
\end{tabular}

on which track losses occurred (typically caused by a blink) were also excluded from the analyses (about 3\% of the trials). Analyses were performed with both subjects $\left(t_{1} ; F_{1}\right)$ and items $\left(t_{2} ; F_{2}\right)$ treated as random effects.

English versus Spanish. Analyses comparing the English and Spanish target word data revealed consistent differences between the two types of target words. Thus, subjects were more likely to skip the target word when it was in English (14\%) than when it was in Spanish (9\%) $\left[t_{1}(31)=2.92, p<.01 ; t_{2}(62)=2.34, p<.01\right]$. When target words were fixated, first fixation durations were shorter for English targets $(258 \mathrm{msec})$ than for Spanish targets $(292 \mathrm{msec})\left[t_{1}(31)=7.05, p<.001 ; t_{2}(62)=6.79\right.$, $p<.001$ ], as were gaze durations (308 $\mathrm{msec}$ for English and $425 \mathrm{msec}$ for Spanish) $\left[t_{1}(31)=6.40, p<.001 ; t_{2}(62)=\right.$ $10.47, p<.001]$. These results are not surprising given that other researchers have previously reported that bilingual subjects have difficulties identifying words in one language that immediately follow words in an alternate language (see, e.g., Grainger \& O'Regan, 1992; Grosjean, 1988). Therefore, given that there are two separate distributions to be considered in the present experiment, one for English targets and one for Spanish targets, 2 (constraint: high vs. low) $\times 2$ (frequency: high vs. low) analyses of variance (ANOVAs) were performed for each language independently.

English target words. There were clear effects of constraint for reading sentences containing English target words: Subjects were more likely to skip a target word when it was constrained by the context $(17 \%)$ than when it was not $(11 \%)\left[F_{1}(1,31)=12.45, M S_{\mathrm{e}}=21, p<.001\right.$; $\left.F_{2}(1,62)=14.44, M S_{\mathrm{e}}=18, p<.001\right]$. Furthermore, first fixation durations were shorter on high-constraint target words $(253 \mathrm{msec})$ than on low-constraint target words

Table 2

Language Histories of Subjects in Experiments 1 and 2

\begin{tabular}{lcc}
\multicolumn{1}{c}{ Characteristics } & $\begin{array}{c}\text { Experiment } \\
(N=32)\end{array}$ & $\begin{array}{c}\text { Experiment 2 } \\
(N=32)\end{array}$ \\
\hline Mean age (in years) & 22.3 & 21.6 \\
Mean number of years in the U.S. & 9.3 & 8.5 \\
Mean number of years in U.S. schools & 8.5 & 8.3 \\
Mean number of years experience with English & 15.9 & 15.1 \\
Mean number of years experience with Spanish & 21.4 & 21.4 \\
Average self-rating on ability (10-point scale) to: & & \\
Read/write English & 8.8 & 9.3 \\
Read/write Spanish & 9.6 & 9.7 \\
Speak English & 9.3 & 9.3 \\
Speak Spanish & 9.9 & 9.8 \\
\hline
\end{tabular}


$(266 \mathrm{msec})\left[F_{1}(1,31)=3.24, M S_{\mathrm{e}}=848, p=.08 ; F_{2}(1,62)=\right.$ 4.23, $\left.M S_{\mathrm{e}}=1,210, p<.05\right]$, as were gaze durations (301 msec for high-constraint targets and $319 \mathrm{msec}$ for low-constraint target words), though this effect was not significant either by subjects $\left[F_{1}(1,31)=2.87, M S_{\mathrm{e}}=\right.$ $6,678, p<.10]$, or by items $\left[F_{2}(1,62)=2.56, M S_{\mathrm{e}}=2,779\right.$, $p<.12]$.

In addition to the strong effects of constraint, there were also effects of word frequency. Although high-frequency words were skipped more often $(15 \%)$ than were lowfrequency words $(12 \%)$, the effect was not significant $(F \mathrm{~s}<1)$. However, frequency did influence the fixation time on the word. In particular, subjects had shorter gaze durations on high-frequency words $(290 \mathrm{msec})$ than on low-frequency words $(325 \mathrm{msec})\left[F_{1}(1,31)=18.72, M S_{\mathrm{e}}=\right.$ $\left.2,034, p<.001 ; F_{2}(1,62)=13.17, M S_{\mathrm{e}}=1,815, p<.001\right] .^{4}$

The results from our bilingual subjects reading sentences containing English target words are important for three reasons. First, they replicate prior research in demonstrating that (1) high-constraint target words are skipped more frequently than are low-constraint words (Balota et al., 1985; Ehrlich \& Rayner, 1981), (2) when low- and high-constraint words are initially fixated, low-constraint words are fixated longer than are high-constraint words (Balota et al., 1985; Ehrlich \& Rayner, 1981; Schustack et al., 1987; Zola, 1984), and (3) low-frequency words are fixated longer than high-frequency words (Inhoff \& Rayner, 1986; Rayner \& Duffy, 1986; Rayner et al., 1989). Second, the data are important because they validate the norming data in demonstrating that the constraint variable was effective. Third, the data also further document our assertion that the subjects were highly fluent in both languages and relatively balanced bilingual readers, since their pattern of data replicates that of prior studies carried out with monolingual English readers.

Spanish target words. When reading sentences containing Spanish target words, subjects skipped highconstraint targets $(12 \%)$ more frequently than they did low-constraint targets $(8 \%)\left[F_{1}(1,31)=4.99, M S_{\mathrm{e}}=25\right.$, $\left.p<.05 ; F_{2}(1,62)=4.55, M S_{\mathrm{e}}=23, p<.05\right]$. However, the more interesting findings for Spanish target words have to do with the fixation time measures, particularly the first fixation duration data. Subjects had shorter first fixation durations for high-frequency words $(280 \mathrm{msec})$ than for low-frequency words $(304 \mathrm{msec})\left[F_{1}(1,31)=\right.$ $12.18, M S_{\mathrm{e}}=1,504, p<.01 ; F_{2}(1,62)=10.39, M S_{\mathrm{e}}=$ $1,398, p<.01]$. But, the most critical finding in these results in comparison with those for English target words (Figure 1) was the significant frequency $\times$ constraint interaction $\left[F_{1}(1,31)=8.28, M S_{\mathrm{e}}=1,376, p<.01 ; F_{2}(1,62)=\right.$ $\left.6.51, M S_{\mathrm{e}}=1,550, p<.05\right]$. Post hoc tests performed on the subject means for this interaction showed a significant effect of constraint for both high- and lowfrequency words; however, the effect was not in the same direction for both types of words. For low-frequency words, subjects had shorter fixation durations $(p<.05)$ in the high-constraint condition $(293 \mathrm{msec})$ than in the low-constraint condition $(315 \mathrm{msec})$. For high-frequency (a)

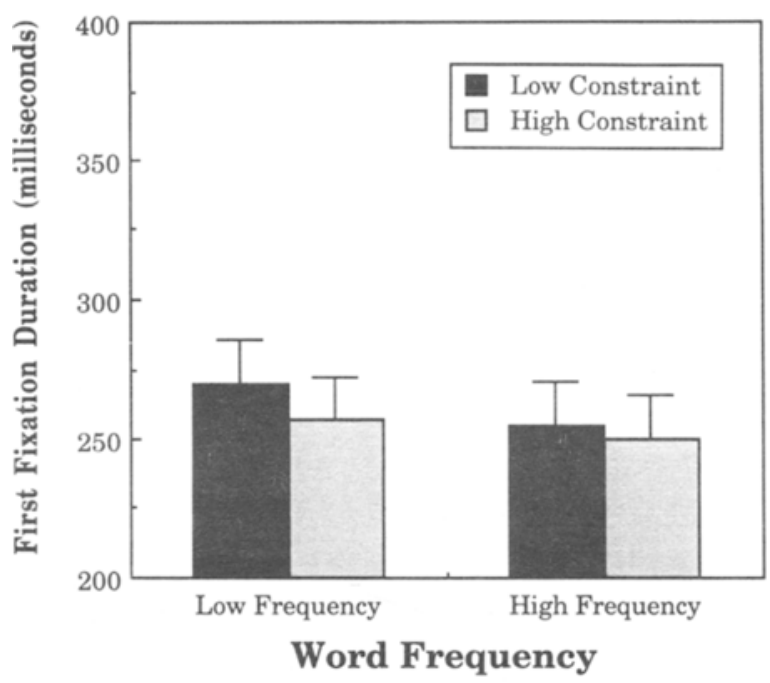

(b)

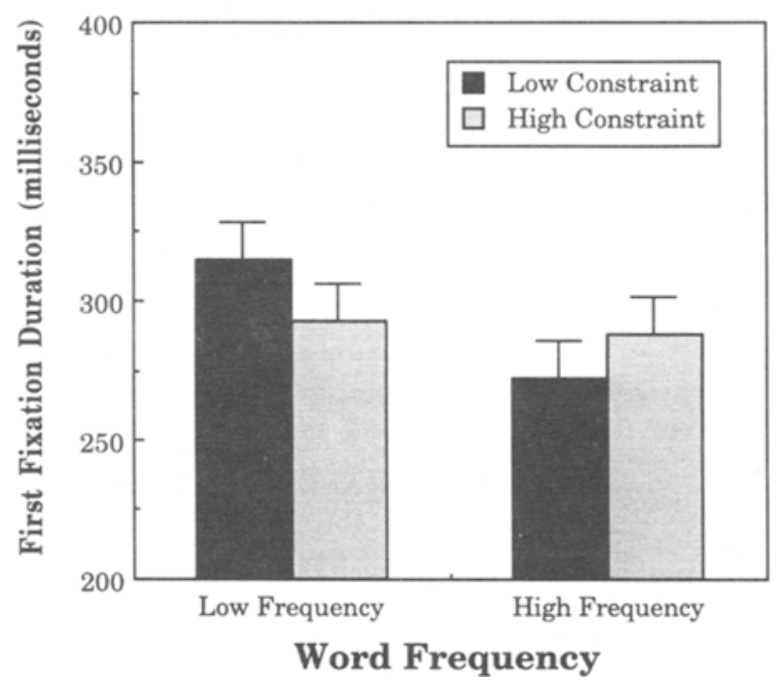

Figure 1. First fixation durations for (a) English target words and (b) Spanish target words as a function of word frequency and sentence constraint. Error bars are based on $95 \%$ within-subject confidence intervals.

words, subjects had shorter fixations $(p<.05)$ in the low-constraint condition $(272 \mathrm{msec})$ than in the highconstraint condition ( $288 \mathrm{msec})$.

When gaze duration was examined (Figure 2), there was a significant main effect of word frequency, with shorter durations for high-frequency words ( $396 \mathrm{msec})$ than for low-frequency words $(453 \mathrm{msec})\left[F_{1}(1,31)=18.46\right.$, $M S_{\mathrm{e}}=5,686, p<.001 ; F_{2}(1,62)=10.76, M S_{\mathrm{c}}=3,344, p<$ $.01]$. Although readers fixated for less time on highconstraint $(413 \mathrm{msec})$ targets than on low-constraint $(436 \mathrm{msec})$ targets, the effect was not significant $(p \mathrm{~s}>$ .10 ), and, more importantly, the interaction of frequency $x$ constraint (which was significant for first fixation duration) was not significant in either the analysis by subjects or by items $\left(F_{\mathrm{S}}<1\right)$. 


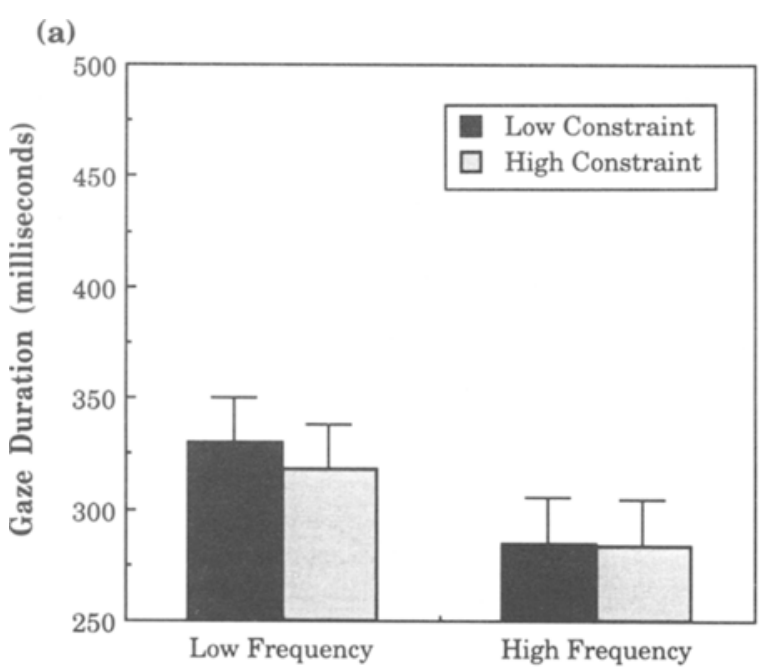

Word Frequency

(b)

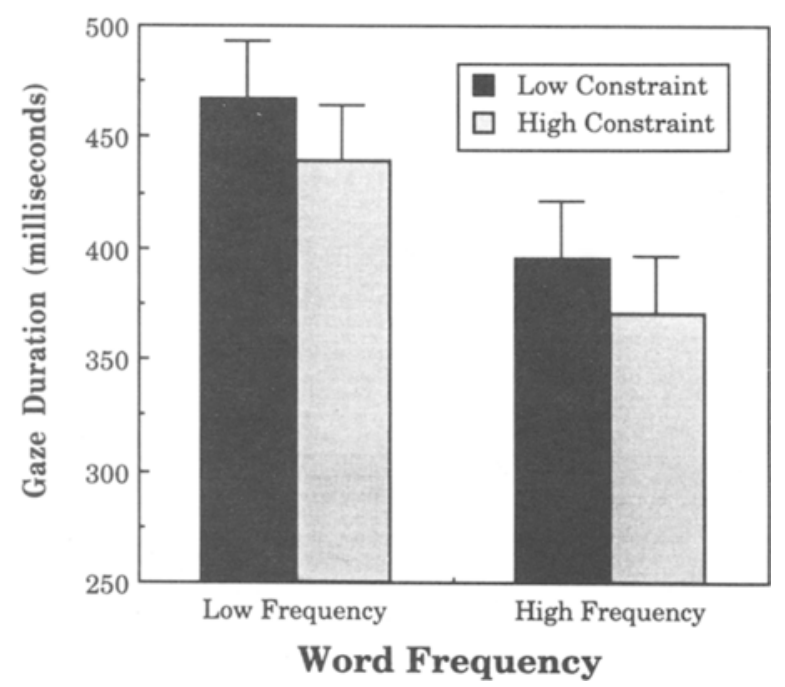

Figure 2. Gaze durations for (a) English target words and (b) Spanish target words as a function of word frequency and sentence constraint. Error bars are based on $95 \%$ within-subject confidence intervals.

The most important result in Experiment 1 was the finding of an interaction between word frequency and sentence constraint for Spanish target words but not for English target words for first fixation duration. This result suggests that sentence constraint influences the generation not only of semantic feature restrictions for upcoming words, but also of lexical features. Subjects experienced interference while processing high-frequency Spanish words embedded in highly constrained sentences. It appears that the high-frequency Spanish word matched the generated set of restricted semantic features but did not match the generated lexical features when the word appeared in the alternate language. This result is similar to that reported by Schwanenflugel and LaCount (1988), who found that words semantically related to an expected target word produced interference, but the processing of the actual target word itself did not. When the Spanish target words were of lower frequency, lexical access for the Spanish word was slower and more time may have been available to resolve potential mismatches between conceptual and lexical information.

In contrast, the results for gaze durations were similar for both English and Spanish target words. There was no word frequency $\times$ sentence constraint interaction for Spanish target words. Recall that gaze durations include all of the fixations on a word before the reader leaves that word. In other words, gaze durations represent an increase in processing time (due to additional fixations on the word) over first fixations. The fact that the interaction was not significant for Spanish target words could have been due to the subjects' ability to process the target words more fully and integrate them more readily into the sentence context, given the extra time.

\section{EXPERIMENT 2 \\ Word Naming in Mixed-Language RSVP Sentences}

A possible criticism of Experiment 1 is that subjects always knew which word was the target in the sentences containing a Spanish word, but they did not have the same information about which word was the critical target in the all-English sentences. To determine whether this difference accounted for our results, and also to obtain converging evidence regarding the locus of the interaction observed in the first fixation and regression data, we conducted Experiment 2 using the RSVP paradigm.

In Experiment 2, the set of sentences used in Experiment 1 was presented to subjects one word at a time, and the subject's task was to name the capitalized target word, which appeared in either English or in Spanish. It has been argued that response times using this procedure reflect processes occurring during lexical access and are not affected by postlexical integration (Masson, 1986; Simpson, Peterson, Casteel, \& Burgess, 1989). If this is the case, the pattern of results obtained in Experiment 2 should be similar to that found for first fixations in Experiment 1 . However, evidence from the literature on code-switching suggests that naming results might differ from those obtained from the eye movement study, since naming involves production as well as lexical access and retrieval. Kolers (1966) had French-English bilinguals read short passages in either English or in French, or passages that contained phrases from both languages intermixed. In the mixed-language passages, several words were switched within each sentence. He found that bilinguals took no longer to silently read the mixed-language passages than they did to read those that appeared in a single language. In contrast, it took subjects longer to read a mixed passage aloud than to read a single-language passage aloud. Although this study has been criticized on the grounds that the mixing of languages was done in a random manner (see, e.g., Grosjean \& Soares, 1986), 
these results suggest that when subjects are asked to name a code-switched word aloud, they might experience a delay while deciding which lexicon to search, engaging in phoneme and syllable specification before producing a response. This delay in processing might allow for postlexical processing and integration to occur. If this interpretation is correct, one might expect a different pattern of results (perhaps one similar to that found for the gaze duration measure reported above) for naming Spanish words aloud in the current experiment as compared with simply reading them as in Experiment 1.

\section{Method}

\section{Subjects}

Thirty-two Spanish-English bilinguals participated as subjects in Experiment 2. Like the subjects in Experiment 1, they were recruited from the University of Massachusetts. None had participated in Experiment 1. They were highly fluent in both English and Spanish and had lived in the United States for an average of 8.5 years. All subjects had normal or corrected-to-normal vision. An experimental session lasted approximately $30 \mathrm{~min}$, and subjects were paid $\$ 3.00$ for their participation.

\section{Materials \\ The materials used in Experiment 2 were identical to those used in Experiment 1 with the following exceptions. Only the sentences were shown in Experiment 2, and all target words were displayed in uppercase letters so that subjects could identify which word re- quired a response. Also, subjects were not given comprehension questions in the RSVP study.}

\section{Procedure}

Subjects were seated in front of an IBM monitor and were given instructions on the computer screen as well as verbally. Each subject saw 64 sentences presented in the following manner. Before each trial, a fixation cross was displayed on the screen. Subjects were instructed to fixate at the center of the screen and press the space bar to begin a trial. After the subject pressed the space bar, the first word in the sentence replaced the fixation cross in the center of the screen. This word was then replaced by the next word in the sentence, and the entire sentence was presented in this fashion, one word at a time. The presentation rate was $100 \mathrm{msec}$ per word, with a 50 -msec interstimulus interval. Within each sentence, a single target word was displayed entirely in uppercase letters. Subjects were instructed to read each sentence to themselves as it was displayed on the screen and to name the word printed in uppercase letters aloud as quickly and as accurately as possible. The target word was presented for the same length of time as the other words in the sentence. A voice-activated relay was interfaced with the computer, and naming latencies were recorded from the onset of the target word. Subjects' responses were also tape-recorded so that their responses could be analyzed for errors.

Subjects were shown 10 practice sentences at the beginning of the session to familiarize them with the procedure. Half of the sentences were all in English, and the other half contained Spanish target words. These sentences did not appear on any experimental list, and all subjects received the same practice block.

After the computer portion of the experiment, subjects were asked to complete the language history questionnaire described in Experiment 1 .

\section{Results and Discussion}

A summary of subjects' language experience for Experiment 2 can be found in Table 2 . The subjects in this experiment were native Spanish speakers with a mean age of 21.6 years and reported having an average of 15.1 years of experience with the English language. They rated themselves higher in their ability to read and write in Spanish than in English, but this difference was not significant $[t(31)=1.36, p>.05]$. They also 1 ated themselves higher in their ability to speak in Spanish than in English $[t(31)=2.03, p<.05]$. Again, on both measures and in both languages, subjects reported mean ratings on the high end of the scale and appeared to be fluent in both languages.

The profile of language experience across the two samples of subjects in Experiments 1 and 2 was very similar. Analyses were conducted on the questionnaire data across the two experiments to compare the two groups of subjects on their experience with their two languages. There were no significant differences between the two groups of subjects on the mean number of years of experience reported for English and Spanish, or on their mean self-ratings on their abilities to read and speak in both languages $(p \mathrm{~s}>.05)$.

\section{Naming Latencies}

Analyses were performed on means computed for each subject or each item, in each condition. ${ }^{5}$ Naming latencies over $2,500 \mathrm{msec}$ or under $300 \mathrm{msec}$ were treated as outliers. In addition, response times that exceeded $2.5 S D$ above the mean for each subject were considered outliers. Outliers constituted less than $2 \%$ of the data overall and were not included in the analyses on correct responses reported here.

English versus Spanish. The results for mean naming latencies on target words appear in Figure 3. Overall, subjects took longer to name target words in Spanish $(757 \mathrm{msec})$ than in English ( $730 \mathrm{msec})\left[t_{1}(31)=1.89, p<\right.$ .05 , one-tailed; $\left.t_{2}(62)=2.77, p<.01\right]$. As in Experiment 1 , separate analyses were conducted for the English and Spanish target words.

English target words. As in Experiment 1, subjects responded faster to English target words embedded in highconstraint sentences $(716 \mathrm{msec})$ than in low-constraint sentences $(744 \mathrm{msec})\left[F_{1}(1,31)=7.30, M S_{\mathrm{e}}=3,262, p<\right.$ $\left..01 ; F_{2}(1,62)=2.35, M S_{\mathrm{e}}=3,227, p<.13\right]$. Furthermore, subjects responded faster to high-frequency words (715 msec) than to low-frequency words $(746 \mathrm{msec})$, but the effect was not significant either by subjects $\left[F_{1}(1,31)=2.62, M S_{\mathrm{e}}=1,384, p=.12\right]$ or by items $\left(F_{2}<1\right)$.

The pattern of results for the naming data for English target words was very consistent with the data obtained in Experiment 1. Comparing the size of effects across the two experiments (using gaze duration from Experiment 1), the constraint effect was $18 \mathrm{msec}$ in Experiment 1 and $28 \mathrm{msec}$ in Experiment 2; the word frequency effect was $35 \mathrm{msec}$ in Experiment 1 and $31 \mathrm{msec}$ in Experiment 2. These results are also quite consistent with results reported by Schilling, Rayner, and Chumbley (1996), who found that the size of the frequency effect was comparable in gaze duration and naming, with the size of the ef- 
(a)

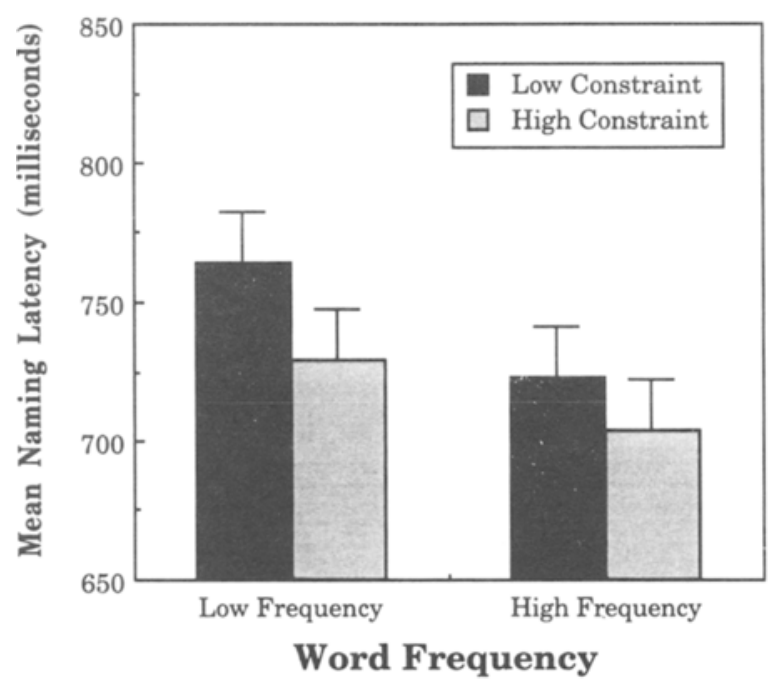

(b)

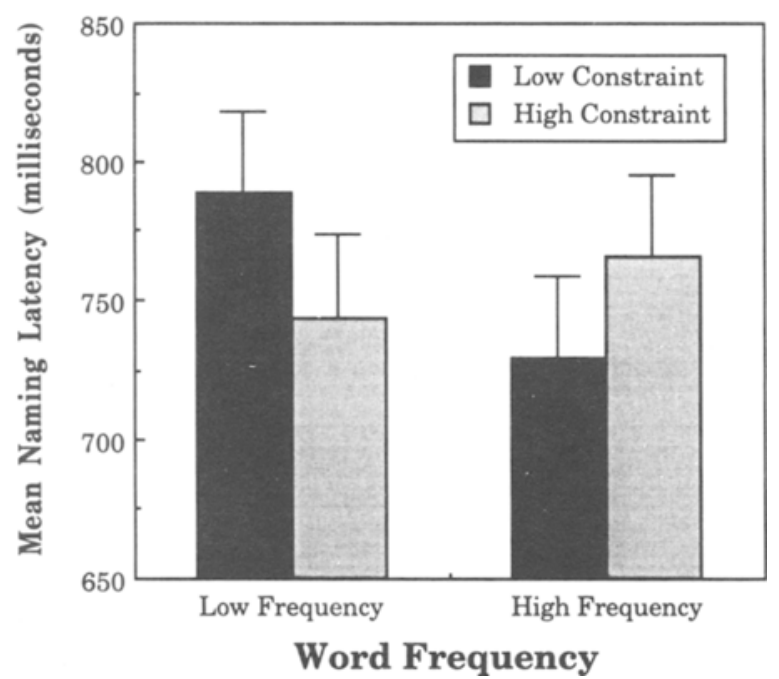

Figure 3. Mean naming latencies for (a) English target words and (b) Spanish target words as a function of word frequency and sentence constraint. Error bars are based on $95 \%$ within-subject confidence intervals.

fect smaller in first fixation duration (exactly the same pattern found here).

Spanish target words. The results for Spanish target words were very similar to those observed in Experiment 1 for first fixation durations on the same words (compare Figures 1 and 3). Although there was a trend for subjects to respond faster to high-frequency target words $(747 \mathrm{msec})$.than to low-frequency target words $(767 \mathrm{msec})$, this effect was only marginally significant for subjects $\left[F_{1}(1,31)=3.31, M S_{\mathrm{e}}=3,640, p<.08\right]$ and not significant for items $(p>.10)$. More importantly, however, the frequency $\times$ constraint interaction showed the same pattern as that obtained in Experiment $1\left[F_{1}(1,31)=\right.$ $8.11, M S_{\mathrm{e}}=6,707, p<.01 ; F_{2}(1,62)=2.25, M S_{\mathrm{e}}=2,074$, $p<.14]$. Post hoc tests performed on the subject means revealed that for low-frequency words, subjects responded faster $(p<.05)$ to words in the high-constraint condition $(744 \mathrm{msec})$ than to words in the low-constraint condition $(789 \mathrm{msec})$. For high-frequency words, the reverse was true. Subjects responded faster $(p<.05)$ to target words embedded in low-constraint sentences $(729 \mathrm{msec})$ than to the same words embedded in high-constraint sentences $(766 \mathrm{msec}){ }^{6}$

\section{Error Rates}

Errors in naming included cases in which subjects named some other word in the sentence, misread a word, or failed to trigger the voice key. More errors were made on Spanish target words $(13 \%)$ than on English target words $(9 \%)\left[t_{1}(31)=1.75, p<.05\right.$, one-tailed; $t_{2}(63)=1.61, p<$ .06 , one-tailed]. A separate analysis performed on the error data for English revealed no significant main effects or interactions $(p s>.10)$, with error rates ranging between $7 \%$ and $11 \%$. For Spanish target words, subjects produced more naming errors for low-frequency words $(18 \%)$ than for high-frequency words $(8 \%)\left[F_{1}(1,31)=\right.$ $20.02, M S_{\mathrm{e}}=161, p<.001 ; F_{2}(1,62)=10.71, M S_{\mathrm{e}}=22$, $p<.01]$. No other effects were significant ( $p \mathrm{~s}>.10$ ).

To summarize the main finding from Experiment 2, the data for naming latencies using the RSVP paradigm closely paralleled the first fixation duration data from Experiment 1. Across the two experiments, we obtained evidence for an interaction between word frequency and constraint for Spanish, but not for English, target words. This interaction appears to be the result of an increase in reading and naming times for high-frequency Spanish target words embedded in high-constraint English sentences. In addition, the similarity of these results across tasks fails to support Kolers's (1966) claim that the production of code-switched words should differ significantly from the silent reading of those words.

The pattern of results suggests that fluent bilingual subjects cannot take advantage of the semantic restrictions that highly constrained contexts provide when the target word is high frequency and appears in the alternate language. Thus, it appears that the effects of sentence constraint are to generate feature restrictions simultaneously about both the meaning and the lexical form of upcoming words.

\section{GENERAL DISCUSSION}

The results of both experiments suggest that sentence constraint influences not only conceptual or semanticlevel expectations about upcoming words in a sentence, but also specific lexical-level expectations for the form in which those words appear. The sentence constraint effects occurred early in the course of processing, as evidenced by the frequency $\times$ constraint interaction present for Spanish target words in the first fixation data in Experiment 1. 
For low-frequency words in Spanish, first fixation durations were shorter when these words were embedded in high-constraint sentences than when they were in lowconstraint sentences. The reverse was true for highfrequency words. Subjects had longer first fixation times on these words in high-constraint sentences than in lowconstraint sentences. Although the high-frequency Spanish words matched the conceptual-level features generated by the context, the lexical-level features were not matched.

The striking interaction found in the first fixation duration and naming data for the Spanish targets is all the more impressive given the fact that when our bilingual subjects read sentences containing English target words, their data replicated earlier findings for monolingual readers. Specifically, their data for reading English target words revealed effects of contextual constraint (both in first fixation duration and gaze duration and in the probability of skipping a target word) and word frequency (in gaze duration).

The naming data in Experiment 2 for Spanish target words followed a pattern similar to that of the first fixation data. Namely, the pattern of interaction reported for first fixation durations was also found in naming. Lowfrequency Spanish target words were named more rapidly in highly constrained sentence contexts than in less constrained contexts, but the reverse was true for the highfrequency Spanish targets. We can thus reject the hypothesis that the eye movement data reflected a difference in performance for targets in the two languages because subjects did not know which word was the target in the allEnglish sentences. In Experiment 2, subjects had knowledge of the target word for both languages, yet virtually the same pattern of results was obtained.

Other recent studies have also shown similar effects of context on sentence processing using eye movements and RSVP/reaction time methods (Duffy et al., 1989; Morris, 1994). The eye movement methodology has been used in investigations of context effects, as it provides a measure of processing free from the decision-making strategies that may be involved in lexical decision tasks (Balota \& Chumbley, 1984; Balota \& Lorch, 1986; Lorch, Balota, \& Stamm, 1986; Lupker, 1984; Seidenberg et al., 1984). This methodology has the added advantage that it does not include the extra processing time involved in naming and pronunciation (see Neely, 1991, for a recent review of task differences). However, the results reported here suggest that naming tasks can produce effects similar to those produced with silent reading of the target words using the eye movement methodology (see also Schilling et al., 1996). On the other hand, Schustack et al. (1987) found a different pattern for fixation time and naming time when the same set of materials was used in two different experiments. Thus, some caution is needed in generalizing from naming to reading depending on the exact nature of the experimental manipulation.

The pattern of results was more consistent between first fixation and naming than between first fixation and gaze duration or gaze duration and naming. The difference between the first fixation data and the gaze duration data in the current experiments may have been the result of a greater degree of integration for gaze durations with the increase in processing time. From first fixations to gaze durations, the pattern of results for Spanish target words begins to approximate the pattern for English target words, indicating that with the extra processing time, subjects had the opportunity to resolve the lexical mismatch between the expected target word and the one actually presented. However, it is interesting to note that the process of integration seems to entail a cost, since the overall difference in fixation times on English and Spanish target words becomes larger from the first fixation data to the gaze duration data. Subjects' mean first fixations were $34 \mathrm{msec}$ longer for Spanish target words than for English target words, while the difference in the gaze duration data was $117 \mathrm{msec}$. Thus, it appears that subjects took an increasing amount of time to process the Spanish target words as the number of fixations made on the target words increased.

Other evidence also suggests that once postaccess integration has occurred, the exact form in which a concept is presented is no longer salient. For example, Kroll and Borning (1987) had English-Spanish bilinguals make lexical decisions to English or Spanish target words following the presentation of English sentence fragments. Target words were either related or unrelated to the sentence contexts. Subjects showed similar context effects for English and Spanish target words, although responses were longer in the Spanish condition. These results are consistent with the idea that once postaccess integration occurs, performance should be similar across a bilingual's two languages.

Several mechanisms may be responsible for the effects of sentence constraint on the recognition of upcoming words that have been reported here. Schwanenflugel (Schwanenflugel \& LaCount, 1988; Schwanenflugel \& Shoben, 1985) suggested that sentence constraint determines the number of semantic featural descriptions that are generated by subjects as they read a sentence. When sentences are of low constraint, subjects may generate fewer feature restrictions, thereby leading to facilitation for a wide variety of possible completions. For high-constraint sentences, subjects can generate a large number of features leading to the most expected completion of a sentence. Facilitation will be shown for words that match the expected feature set but that do not mismatch any of the features generated from the sentence. Schwanenfluge! and LaCount found facilitation only for the expected words in a sentence context; semantically related words did not produce facilitation.

The current work extends this model by showing that subjects generate feature restrictions that are both semantic and lexical in nature. By using a mixed-language paradigm, we were able to simultaneously manipulate both conceptual and lexical-level features of target words. We found that word recognition was facilitated to the de- 
gree that both the expected semantic feature restrictions and the lexical feature restrictions were matched by the target word. If the semantic or conceptual restrictions were met, but a mismatch occurred on the lexical level, interference occurred for both first fixation durations and naming latencies. These results are compelling given that the findings were consistent across different tasks and different subjects.

Although one might be tempted to argue that the current set of results may be unrepresentative given that subjects were processing sentences in their second language, there are reasons to reject this hypothesis. First, all of the measures used to determine the subjects' fluency in English and in Spanish indicate that subjects were highly fluent in both languages and had similar reading abilities in both languages. Second, the eye movement data for the all-English passages and sentences were similar to data previously reported in the literature for monolingual, native English subjects under similar conditions (see, e.g., Rayner \& Pollatsek, 1989, for a review of the relevant eye movement literature). If subjects were not proficient in their second language, one would expect to find evidence of difficulty in processing in that language. Finally, the fact that a distinct interaction between word frequency and sentence constraint was observed for Spanish targets both in first fixations and in naming times suggests that subjects did not adopt a peculiar strategy determined simply by the overall match between the target and sentence languages. Thus, the results presented in this paper suggest that the performance of fluent bilinguals can be used to reveal constraints in language processing at a number of different levels of representation.

The present study demonstrates how bilingualism can be used as a tool for exploring sentence constraint effects during reading. Because past research suggests that fluent bilinguals have shared conceptual representations across languages, experiments may be designed to take advantage of the fact that a single concept can be accessed by two distinct lexical forms. Like research on lexical ambiguity, bilingual research permits the separation of lexical and conceptual contributions to reading and comprehension. However, unlike research on lexical ambiguity, research with bilinguals is not limited to a small set of ambiguous words. Thus, the effects of both conceptual and lexical information can be studied within a single subject.

In conclusion, the main result in this set of experiments was that sentence context effects were influenced by both semantic/conceptual information and lexical information. These results were found using both the eye movement methodology and naming in an RSVP procedure. In contrast to the lexical decision task, these tasks do not include a binary decision and should be free from the use of postlexical checking strategies by subjects. The results are in line with results reported by Schustack et al. (1987), Morris (1994), and Schwanenflugel and LaCount (1988), which we discussed earlier, as well as with results reported by Masson (1986), O'Seaghdha (1989), and Simpson et al. (1989), indicating that sentence context effects reflect both lexical-level and messagelevel processing. In short, it appears that sentence context effects are the result of processing occurring at several levels of language representation and are not simply a reflection of intralexical priming.

\section{REFERENCES}

Altarriba, J. (1992). The representation of translation equivalents in bilingual memory. In R. J. Harris (Ed.), Cognitive processing in bilinguals (pp. 157-174). Amsterdam: Elsevier, North-Holland.

Balota, D. A., \& Chumbley, J. I. (1984). Are lexical decisions a good measure of lexical access? The role of word frequency in the neglected decision stage. Journal of Experimental Psychology: Human Perception \& Performance, 10, 340-357.

BaLOTA, D. A., \& LoRCH, R. F. (1986). Depth of automatic spreading activation: Mediated priming effects in pronunciation but not in lexical decision. Journal of Experimental Psychology: Learning, Memory, \& Cognition, 12, 336-345.

Balota, D. A., Pollatsek, A., \& Rayner, K. (1985). The interaction of contextual constraints and parafoveal visual information in reading. Cognitive Psychology, 17, 364-390.

Barrera, R. B., \& Crawford, A. N. (1987). Portales: Guia del maestro. Boston: Houghton Mifflin.

BLOOM, P. A., \& FisCHLER, I. (1980). Completion norms for 329 sentence contexts. Memory \& Cognition, 8, 631-642.

Chen, H-C., \& Leung, Y-S. (1989). Patterns of lexical processing in a nonnative language. Journal of Experimental Psychology: Learning, Memory, \& Cognition, 15, 316-325.

CHEN, H-C., \& NG, M-L. (1989). Semantic facilitation and translation priming effects in Chinese-English bilinguals. Memory \& Cognition, 17, 454-462

DE GROOT, A. M. B. (1992). Determinants of word translation. Journal of Experimental Psychology: Learning, Memory, \& Cognition, 18, 1001-1018.

Duffy, S. A., Henderson, J. M., \& Morris, R. K. (1989). The semantic facilitation of lexical access during sentence processing. Journal of Experimental Psychology: Learning, Memory, \& Cognition, 15, 791-801.

EhrLich, S. F., \& Rayner, K. (1981). Contextual effects on word perception and eye movements during reading. Journal of Verbal Learning \& Verbal Behavior, 20, 641.655.

Fischler, I. (1985). Word recognition, use of context, and reading skill among deaf college students. Reading Research Quarterly, 20, 203218.

Fischler, I., \& Bloom, P. A. (1980). Rapid processing of the meaning of sentences. Memory \& Cognition, 8, 216-225.

FORSTER, K. I. (1981). Priming and the effects of sentence and lexical contexts on naming time: Evidence for autonomous lexical processing. Quarterly Journal of Experimental Psychology, 33A, 465-496.

GlanZER, M., \& DuARTE, A. (1971). Repetition between and within languages in free recall. Journal of Verbal Learning \& Verbal Behavior, 10, 625-630.

Grainger, J., \& O'Regan, K. (1992). A psychophysical investigation of language priming effects in two English-French bilinguals. European Journal of Cognitive Psychology, 4, 323-339.

Grosjean, F. (1988). Exploring the recognition of guest words in bilingual speech. Language \& Cognitive Processes, 3, 233-274.

Grosjean, F., \& Soares, C. (1986). Processing mixed language: Some preliminary findings. In J. Vaid (Ed.), Language processing in bilinguals: Psycholinguistic and neurological perspectives (pp. 145170). Hillsdale, NJ: Erlbaum.

INHOFF, A. W. (1984). Two stages of word processing during eye fixations in the reading of prose. Journal of Verbal Learning \& Verbal Behavior, 23, 612-624.

INHOFF, A. W., \& RAYNER, K. (1986). Parafoveal word processing during eye fixations in reading. Perception \& Psychophysics, 40, 431-439. 
Juilland, A., \& Chang-Rodriguez, E. (1964). Frequency dictionary of Spanish words. The Hague: Mouton.

KOLERS, P. A. (1966). Reading and talking bilingually. American Journal of Psychology, 79, 357-376.

KROLL, J. F, \& BORNING, L. (1987, November). Shifting language representations in novice bilinguals: Evidence from sentence priming. Paper presented at the annual meeting of the Psychonomic Society, Seattle.

Kroll, J. F., \& CurLey, J. (1988). Lexical memory in novice bilinguals: The role of concepts in retrieving second language words. In M. Gruneberg, P. Morris, \& R. Sykes (Eds.), Practical aspects of memory (Vol. 2, pp. 389-395). London: Wiley.

Kroll, J. F., \& ShOLL, A. (1992). Lexical and conceptual memory in fluent and nonfluent bilinguals. In R. J. Harris (Ed.), Cognitive processing in bilinguals (pp. 191-204). Amsterdam: Elsevier, NorthHolland.

Kroll, J. F., \& Stewart, E. (1994). Category interference in translation and picture naming: Evidence for asymmetric connections between bilingual memory representations. Journal of Memory \& Language, 33, 149-174.

KuČERA, H., \& FrANCIs, E. (1967). Computational analysis of presentday American English. Providence, RI: Brown University Press.

LorCh, R. F., Balota, D. A., \& Stamm, E. G. (1986). Locus of inhibition effects in the priming of lexical decisions: Pre- or postlexical access. Memory \& Cognition, 14, 95-103.

LUPKER, S. J. (1984). Semantic priming without association. A second look. Journal of Verbal Learning \& Verbal Behavior, 23, 709-733.

MAsson, M. E. J. (1986). Comprehension of rapidly presented sentences: The mind is quicker than the eye. Journal of Memory \& Language, 25, 588-604.

MEYER, D. E., \& RUDDY, M. G. (1974, April). Bilingual word recognition: Organization and retrieval of alternative lexical codes. Paper presented at the annual meeting of the Eastern Psychological Association, Philadelphia.

Monsell, S. (1991). The nature and locus of word frequency effects in reading. In D. Besner \& G. W. Humphreys (Eds.), Basic processes in reading ( $\mathrm{pp} .148-197)$. Hillsdale, $\mathrm{NJ}$ : Erlbaum.

MORRIS, R. K. (1994). Lexical and message-level sentence context effects in fixation times in reading. Journal of Experimental Psychology: Learning, Memory, \& Cognition, 20, 92-103.

MORRISON, R. E. (1984). Manipulation of stimulus onset delay in reading: Evidence for parallel programming of saccades. Journal of Experimental Psychology: Human Perception \& Performance, 10, 667-682.

NeELY, J. H. (1991). Semantic priming effects in visual word recognition: A selective review of current findings and theories. In D. Besner \& G. Humphreys (Eds.), Basic processes in reading (pp. 264-336). Hillsdale, NJ: Erlbaum.

O'SEAGHDHA, P. G. (1989). The dependence of lexical relatedness effects on syntactic connectedness. Journal of Experimental Psychology: Learning, Memory, \& Cognition, 15, 73-87.

Pollatsek, A., Lesch, M., Morris, R. K., \& Rayner, K. (1992). Phonological codes are used in integrating information across saccades in word identification and reading. Journal of Experimental Psychology: Human Perception \& Performance, 18, 148-162.

Potter, M. C., So, K-F., von Eckardt, B., \& Feldman, L. B. (1984) Lexical and conceptual representation in beginning and proficient bilinguals. Journal of Verbal Learning \& Verbal Behavior, 23, 23-38.

RAYNER, K. (1978). Eye movements in reading and information processing. Psychological Bulletin, 85, 618-660

RAYNer, K., \& DuFFY, S. A. (1986). Lexical complexity and fixation times in reading: Effects of word frequency, verb complexity, and lexical ambiguity. Memory \& Cognition, 14, 191-201.

Rayner, K., \& Pollatsek, A. (1989). The psychology of reading. Englewood Cliffs, NJ: Prentice-Hall

Rayner, K., Sereno, S. C., Morris, R. K., Schmauder, A. R., \& Clifton, C. E. (1989). Eye movements and on-line comprehension processes. Language \& Cognitive Processes, 4, 21-49.

Rayner, K., Sereno, S. C., \& Raney, G. E. (in press). Eye movement control in reading: A comparison of two types of models. Journal of Experimental Psychology: Human Perception \& Performance.
Schilling, H. E. H., Rayner, K., \& Chumbley, J. I. (1996). Word frequency effects on pronunciation, lexical decision, and eye fixation times: What individual and task differences tell us. Manuscript submitted for publication.

Schustack, M. W., Ehrlich, S. F., \& Rayner, K. (1987). The complexity of contextual facilitation in reading: Local and global influences. Journal of Memory \& Language, 26, 322-340.

SchWANEnflugel, P. J., \& LaCount, K. L. (1988). Semantic relatedness and the scope of facilitation for upcoming words in sentences. Journal of Experimental Psychology: Learning, Memory, \& Cognition, 14, 344-354.

SCHWANENFlugel, P. J., \& Rey, M. (1986). Interlingual semantic facilitation: Evidence for a common representational system in the bilingual. Journal of Memory \& Language, 25, 605-618.

SCHWANENFlugel, P. J., \& SHOBEN, E. J. (1985). The influence of sentence constraints on the scope of facilitation for upcoming words. Journal of Memory \& Language, 24, 232-252.

Seidenberg, M. S., Waters, G. S., Sanders, M., \& Langer, O. (1984). Pre- and postlexical loci of contextual effects on word recognition. Memory \& Cognition, 12, 315-328.

Simpson, G. B., Peterson, R. R., Casteel, M. A., \& Burgess, C. (1989). Lexical and sentence context effects in word recognition. Journal of Experimental Psychology: Learning, Memory, \& Cognition, 15, 88-97.

SNODGRass, J. G. (1984). Concepts and their surface representation. Journal of Verbal Learning \& Verbal Behavior, 23, 3-22.

StANOVICH, K. E., \& WEST, R. F. (1983). On priming by a sentence context. Journal of Experimental Psychology: General, 112, 1-36.

Tzelgov, J., \& HeNIK, A. (1989, July). The insensitivity of the semantic relatedness effect to surface differences and its implications. Paper presented at the First European Congress of Psychology, Amsterdam.

ZoLA, D. (1984). Redundancy and word perception during reading. Perception \& Psychophysics, 36, 277-284

\section{NOTES}

1. The word expectation as used here refers to the automatic generation of a set of features regarding an upcoming word in a sentence context and not a conscious, strategic process engaged in by the reader The same comment applies to our use of the word generate throughout the paper.

2. Although an effort was made to exclude cognates from the stimulus lists, the following three pairs were inadvertently included: gardenjardin; paper-papel; trophy-trofeo. Excluding these items from the analysis did not affect the overall results.

3. Subsequent $t$ tests revealed highly significant differences between the low- and high-frequency target words for both English and Spanish. The distributions were distinct and nonoverlapping

4. The $13-\mathrm{msec}$ difference in first fixation duration ( $253 \mathrm{vs} .266 \mathrm{msec}$ ) was in the right direction, but was not significant.

5. Two items were incorrectly placed in the stimulus lists in Experiment 2 . The target word dedal should have appeared as thimble, its translation. This item incorrectly appeared in the low-frequency/highconstraint condition in Spanish. A second item, the word movie, was capitalized in a sentence in which the word evening should have appeared as the target word. This item was in the high-frequency/lowconstraint condition in English. These items were removed from both the data on subjects' naming latencies and the item data. In the items analysis, overall means for these two items were replaced by the mean of the condition in which each appeared.

6. The weaker effect of items in Experiment 2 may be because naming latencies are typically more sensitive to lexical factors than to conceptual context (Balota \& Chumbley, 1984; Forster, 1981; Seidenberg, Waters, Sanders, \& Langer, 1984). However, one might have expected that the slower naming latencies for the Spanish words would have increased the likelihood of semantic influence and therefore increased the magnitude of the constraint effect in Spanish. If anything, we observed precisely the opposite pattern of results. Subjects were slower to name high-frequency Spanish words when they appeared in highly constrained English sentences. 


\section{APPENDIX}

\section{High- and Low-Constraint Sentences Used in Experiments 1 and 2} (a, High Constraint; b, Low Constraint)

High-Frequency Words

1. letter-carta

a. He needed to put a stamp on the letter before he mailed it.

b. Andrea dropped a letter in the mailbox at the corner.

2. city-ciudad

a. She moved from the country to the city to find a better job.

b. We took a walk in the city before we drove back home.

3. children-niños

a. The playground was filled with children from the nursery next door.

b. We took all of the children home after school in our new van.

4. church-iglesia

a. On Sunday morning we went to church and had lunch with my grandmother.

b. We passed by a church on our way to the supermarket.

5. bridge-puente

a. We crossed over the bridge and entered the old castle.

b. The money was used to replace the bridge after the earthquake.

6. teeth-dientes

a. The dentist told me to brush my teeth after every meal.

b. He lost three teeth and had a black eye after the fight.

7. pool-piscina

a. We went swimming in the pool two hours after lunch.

b. The girls liked the pool but preferred the beach instead.

8. floor-piso

a. Mary decided to sweep the wooden floor with the new broom.

b. We looked on the floor but never found her contact lens.

9. evening-tarde

a. The sun begins to set in the early evening during the summer.

b. They hoped to see a movie this evening after dinner.

10. plane-avión

a. We went to the airport to watch the plane land on the runway.

b. A picture of the plane was kept on a small table next to his bed.

11. blood-sangre

a. The open wound was covered with blood and could not be closed.

b. A small amount of blood was placed into the test tube.

12. question-pregunta

a. She asked a question that had been answered in a previous lecture.

b. He thought that the question of whether to raise taxes would be discussed with great interest.

13. street-calle

a. You need to look both ways before crossing a street as busy as that one.

b. They chose a street that could be easily closed off for the parade.

14. money-dinero

a. He wanted to deposit all of his money at the credit union.

b. He always placed his money on a silver dish on his dresser.

15. garden-jardin

a. Several varieties of tulips were growing in the garden in the spring.

b. He was walking in the garden when he noticed the fire in the barn.

16. chair-silla

a. Mark had a table and a chair in his small office.

b. The blue and white chair was his favorite piece of furniture.

17. sweet-dulce

a. The chocolate cake was too sweet and impossible to eat.

b. He wanted something sweet to serve to his guests after dinner.

18. beach-playa

a. The resort village advertised a long sandy beach and new tennis courts.

b. Kim and Susan drove to the town beach after a long day at the office.

19. newspaper-periódico

a. Gail read about the strike in the newspaper and called her boss.

b. She decided to find a newspaper and check the movie listings. 
APPENDIX (Continued)

20. teacher-maestra

a. He entered the classroom to ask the teacher for help with his assignment.

b. Mary and Jim wanted to ask the teacher for help after class.

21. kitchen-cocina

a. The refrigerator and stove came with the kitchen but they had to buy the dishwasher.

b. Molly enjoyed working in the kitchen evenings and weekends.

22. dream-sueño

a. I woke up in the middle of a vivid dream in which I was taking a trip into outer space.

b. I had a complicated dream in which I was living in my childhood home.

23. rain-lluvia

a. The weather forecast called for clouds and a sixty percent chance of rain or snow.

b. They delayed their trip to Maine because the rain was so heavy the dirt roads were washed away.

24. drink-trago

a. Bill and Ted were so thirsty they ordered a drink as they walked into the restaurant.

b. To make a wonderful $d r i n k$ combine pineapple juice with tropical juices in a blender.

25. window-ventana

a. To install an air conditioner in a casement window requires a special attachment.

b. The house had an especially nice window in the family room.

26. party-fiesta

a. Although Anne was invited to a New Year's Eve party, she didn't like to drive on that night.

b. The elaborate plans for the party were all set when Alan and Nicole decided not to get married.

27. paper-papel

a. The teacher told the children to take out a pencil and a sheet of paper to write down their assignments.

b. The assistant had to decide what type of paper to purchase for the new office computer.

28. morning-mañana

a. The alarm clock went off every morning at exactly 6 a.m.

b. The schedule for the conference included morning and afternoon meetings.

29. market-mercado

a. Eva loved to shop for vegetables and flowers at the local farmer's market in the summer.

b. Pamela wished that she could recreate the image of the market in the small village where she had lived.

30. school-escuela

a. The bus stopped right in front of the elementary school to pick up the youngest children.

b. He was recently hired to work at the new school for children with learning disabilities.

31. forest-bosque

a. In many fairy tales children get lost in the forest where they have frightening encounters.

b. The new state senator was elected because she supported a bill to protect the forest and endangered species.

32. heart-corazón

a. Because it was Valentine's Day, John baked a cake in the shape of a heart and decorated it with a cupid.

b. The ice sculpture was carved in the shape of a heart before it melted away.

Low-Frequency Words

1. oven-horno

a. Sally took the warm cake out of the oven and put it on the table.

b. We went to the store to buy a new oven for our kitchen.

2. mouse-ratón

a. They left the cheese in the trap to catch the mouse that was in the basement.

b. Peter had never seen a mouse in his house before this year.

3. pumpkin-calabaza

a. On Halloween the children carved an orange pumpkin for the front steps.

b. The market had a new variety of pumpkin in the fall.

4. flour-harina

a. The cake recipe required two cups of sifted flour as well as four eggs and a teaspoon of vanilla.

b. The chef always used flour instead of cornmeal when cooking chicken.

5. thief-ladrón

a. The robbery was committed by a thief who was known for his skill in safe cracking.

b. He warned us that the thief had escaped from prison on Wednesday.

6. eagle-águila

a. Flying in the sky overhead was a bald eagle and two small, black hawks.

b. The park had the only surviving eagle of that kind in the world.

7. garbage-basura

a. She walked to the dumpster to throw away the garbage that had been cluttering up the basement.

b. The empty lot was filled with garbage from the neighborhood kids. 


\section{APPENDIX (Continued)}

8. towel-toalla

a. She dried herself off with the towel hanging on the rack.

b. The department store has a towel sale through next Thursday.

9. recipe-receta

a. When baking cookies, Bob always followed the recipe to the letter.

b. Sue asked Fred if she could borrow his recipe for meatloaf.

10. sponge-esponja

a. She wiped up the spilt milk with a sponge that she found under the sink.

b. Jim bought a new sponge at the drugstore in the mall.

11. dessert-postre

a. Following dinner she ordered ice cream for dessert and asked for the bill.

b. The students met downtown for dessert and coffee every Friday.

12. balloon-globo

a. The clown handed a big blue balloon to the little girl.

b. The boy selected a balloon from the bunch and released it.

13. broom-escoba

a. He swept the broken glass with the broom from the supply closet.

b. The children used an old broom, a blanket, and some string to make a hobby horse.

14. stain-mancha

a. The white pants had a big grass stain on the left knee.

b. He was upset to discover a big stain on his brand new necktie.

15. rocket-cohete

a. The scientists were about to launch the rocket when the message was received.

b. Sarah received a toy rocket and a chemistry set for her birthday.

16. cherry-cereza

a. George Washington admitted that he chopped down the cherry tree in his yard.

b. Sue ate the last serving of cherry pie at Thanksgiving dinner.

17. scarf-bufanda

a. She took her mittens and long, woolen scarf out of the storage chest.

b. He selected the longest scarf from the hall closet.

18. cricket-grillo

a. At night you can hear the chirping of a cricket on the back porch.

b. He heard the faint sound of one cricket chirping in the basement.

19. carpet alfombra

a. He requested wall-to-wall shag carpet for his new office.

b. The newly purchased white carpet had not yet been stained by muddy shoes.

20. curtain-cortina

a. She pulled back the plastic shower curtain and stepped into the tub.

b. She sewed a fine hem on the curtain for her daughter's bedroom.

21. bubble-burbuja

a. He cracked his gum and blew a big bubble during the boring class lecture.

b. The wind carried the bubble to the edge of the fountain.

22. button-botón

a. She sewed a small pearl button onto her cardigan sweater.

b. He used an old button to play hopscotch on the sidewalk.

23. apple-manzana

a. Snow White bit into the poisoned apple that the wicked witch had given her.

b. He selected an unspoiled apple from the bin at the supermarket.

24. cheese-queso

a. Cheddar is the best kind of cheese to put on a hot baked potato.

b. Kevin usually put lots of cheese on his hamburger as it was cooking on the grill.

25. earthquake-terremoto

a. Northern California just had a major earthquake last year that was devastating.

b. The first story in the newspaper was about the earthquake that happened in Japan.

26. glove-guante

a. The surgeon slipped his hand into the rubber glove to protect himself during the operation.

b. He returned home to pick up his glove before the baseball game this afternoon.

27. trophy-trofeo

a. The winners of the bowling tournament received an engraved trophy as well as a handsome check.

b. One of the shelves in the room had a trophy on it from the last tennis tournament.

28. turtle-tortuga

a. The pond had a few fish and a small green turtle swimming near the shore.

b. We found a small turtle swimming in the stream behind the barn. 
APPENDIX (Continued)

29. groom - novio

a. The wedding cake had a bride and groom figurine on the top layer.

b. He wanted the shirt to look like the one the groom was wearing at the wedding.

30. spider-araña

a. She gasped as the black widow spider crawled up the side of the staircase.

b. She stared at the spider crawling down her sleeve in the garden.

31. shelf estante

a. He put the book back on the shelf and hurried out of the library.

b. It was placed next to the shelf under the kitchen window.

32. thimble-dedal

a. The seamstress placed the silver thimble on her finger to avoid injury.

b. He often placed an old thimble on the end of his cane in order to make a loud noise.

(Manuscript received November 15, 1994;

revision accepted for publication July 10,1995.) 